\title{
Effect of grain and secondary phase morphologies in the mechanical and damping behavior of Al7075 alloys
}

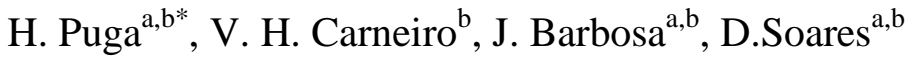 \\ ${ }^{\text {a }}$ Centre for Micro-Electro Mechanical Systems (CMEMS) \\ ${ }^{\mathrm{b}}$ Department of Mechanical Engineering \\ University of Minho, Campus of Azurém, 4800-058 Guimarães - Portugal \\ *Corresponding author: H. Puga (PhD) - puga@dem.uminho.pt
}

\begin{abstract}
The present study evaluates the role of the microstructure in the static and dynamic mechanical behavior of as-cast A17075 alloy promoted by ultrasonic treatment (US) during solidification. The characterization of samples revealed that US treatment promoted grain and intermetallics refinement, changed the shape of the intermetallic phases (equilibrium phases of soluble $\mathrm{M}$ and/or $\mathrm{T}(\mathrm{Al}, \mathrm{Cu}, \mathrm{Mg}, \mathrm{Zn})$ and their insoluble $\mathrm{Al}-\mathrm{Cu}-\mathrm{Fe}$ compounds) and lead to their uniform distribution along the grain boundaries. Consequently, the mechanical properties and damping capacity above critical strain values were enhanced by comparison with values obtained for castings produced without US vibration. This results suggest that the grain and secondary phases refinement by US can be a promising solution to process materials to obtain high damping and high strength characteristics.
\end{abstract}

\section{Keywords}

Ultrasonic Treatment, Intermetallic phases, Grain refinement, Mechanical properties, Damping.

\section{Introduction}

The application of light-alloys, particularly those which are aluminum based, are still a promising solution for the manufacturing of structures for the automotive and aerospace industries. Even though these alloys present an advantage due to their low density and common availability, they generally need to be processed to compete with other common alloys [1]. One 
of the most promising processing techniques to obtain aluminum castings, is to introduce ultrasound (US) processing in their casting route [2].

Although the influence of US treatment on aluminum alloys was already studied in static applications (e.g. the works of Eskin and Eskin [3] and Puga et al. [4]), where both porosity reduction and microstructural modification by US proved to increase static mechanical properties, there are still few evidences of its role in dynamic situations such as those often required in applications in the referred industries.

Superior static mechanical properties, i.e. higher values of yield/ultimate strength and fracture extension, are directly correlated with the microstructure of a given material and the amount of bulk defects. The values of plastic flow stress are related to the grain size by the Hall-Petch relation [5] and the overall values of ultimate tensile strength and elongation can be lowered by the presence of porosities, oxide films and coarse microstructure [6], which can promote stress concentration and crack nucleation.

From a dynamic point of view it is desirable to improve the dissipation of elastic strain energy of mechanical vibration [7], through the internal friction generated by thermal activation and anelastic relaxation. This energy dissipation is related with the morphology of the microstructure, namely the secondary phases, impurity atoms, porosity, grain size and their boundaries [8-9].

This internal friction $\left(\mathrm{Q}^{-1}\right)$ has a relevant role in the viscoelastic properties of materials: it generates a lag time effect that is generally neglected by the classical Hooke's law formulation, being composed by a a stored energy part (Storage modulus - $\mathrm{E}^{\prime}$ ) and a dissipated energy part (Loss modulus - $\mathrm{E}^{\prime \prime}$ ), according to Eq.1.

$$
Q^{-1}=\frac{E^{\prime \prime}}{E^{\prime}}
$$

The internal friction is known to be associated with the dislocation properties of metals at low temperatures and with thermal energy at high temperatures [11], according to thermodynamics and the classical dislocation theory proposed by Granato and Lücke [12]. This internal friction 
due to dislocation mechanism is related with the applied dynamic strain, and the logarithmic decrement $(\delta)$ is characterized by two parts, according to Eq. (2) [13].

$$
\delta=\delta_{0}+\delta_{H}(\varepsilon)
$$

Low values of strain, imply a value of internal friction that is strain independent and assumes the value of $\delta_{0}$, as a result of reversible movements of dislocation and microscopic yielding around the initial pinned positions [14], and is associated to the values obtained by the application of Eq. (3) [15]. Where $\rho$ is the dislocation density and $L_{d}$ is the mean length of dislocation between the weak pinning points. Eq.(4) describes the strain dependent $\left(\delta_{\mathrm{H}}(\varepsilon)\right)$ behaviour when the strain amplitude is increased to values that are higher than the critical strain $\left(\varepsilon_{\mathrm{cr}}\right)$ [13]. Where $\mathrm{F}_{\mathrm{b}}$ is the binding force between dislocations and weak pinning points, $\mathrm{E}$ is the Young's modulus, $\mathrm{L}_{\mathrm{n}}$ is the average dislocation distance between strong pinning points, $\mathrm{b}$ is the magnitude of the Burgers vector, $\mathrm{K}$ is a constant and $\eta$ is the size of solvent to solute atoms.

$$
\begin{gathered}
\delta_{0} \sim \rho L_{d}{ }^{4} \\
\delta_{H}=\frac{\rho F_{B} L_{N}{ }^{3}}{6 b E L_{d}} e^{-\frac{K_{b} \eta}{\varepsilon L_{d}}}
\end{gathered}
$$

Given the primary role of the base matrix in the static and dynamic properties, it is essential to process materials to manipulate the microstructure of $\mathrm{Al}$ alloys. This can be performed by two basic approaches: (i) thermomechanical treatment through plastic deformation in which dynamic recrystallization leads to the formation of small equiaxed grains [16]; (ii) casting processing where two different routes can be followed: chemical (e.g. as demonstrated by Cao and Huang [17], or physical treatment as researched by Chen et al. [18] and Lee et al. [19]. (e.g. a particular physical treatment study concerning the use of US can be found in the work of Tuan et al. [20]).

This paper presents and discusses the effect of the ultrasonic treatment on the microstructure and its role in the static and dynamic mechanical behavior of as-cast A17075 alloy cast in a permanent mold by applying ultrasound indirectly to the melt during the first stages of solidification. 


\section{Experimental procedure}

2.1 Set-up and casting method

The experimental set-up used to perform ultrasonic refinement consisted in a MMM technology US power supply unit, a high power ultrasonic generator $(3000 \mathrm{~W})$, a $\phi 38.1 \mathrm{~mm}$ x $92 \mathrm{~mm}$ Ti6Al4V long acoustic waveguide, an acoustic load composed by a steel die ( $\phi 24 \mathrm{~mm} \times 120$ mm long) and the liquid metal, according to Fig. 1a.

The Al7075 alloy was melted and held inside the crucible at $700{ }^{\circ} \mathrm{C}$ for 15 minutes for homogenization, ultrasonically degassed for 5 minutes and poured in a steel die (pre-heated to $250{ }^{\circ} \mathrm{C}$ ). During cooling US vibration regulated for $400 \mathrm{~W}$ and $20.1 \pm 0.25 \mathrm{kHz}$ frequency was continuously applied to the bottom of the die between the pouring temperature and solidus, and then the metal was allowed to cool until room temperature. For the sake of comparison the alloy was also poured without US treatment.

To assess the effect of grain size and intermetallic phase in the behavior of mechanical and dynamic properties, melts were degassed before pouring at the desired temperature using the MMM ultrasonic technology, to ensure that the density level of bath was identical for every experiment.

\subsection{Microstructure characterization}

Specimens for microstructure characterization were taken from cast samples according to Fig. 1b, by sectioning them perpendicularly to its longitudinal axis, at distances of 10, 40 and $70 \mathrm{~mm}$ from the waveguide/mold interface. Optical microscope (OM) and Scanning Electron Microscope (SEM), with quantitative metallographic analysis capability, were used to evaluate the shape and grain size of constituents. Image-ProPlus software was used to quantify the average grain size and average area fraction of intermetallic phases. The average grain size was measured according to Eq. (5), where $\mathrm{d}$ is the grain size and $\mathrm{A}$ is the grain area. Measurements were carried out according to ASTM E112 Standard. 50 measurements per optical field $(100 \mathrm{x})$ were performed on 5 different fields. 


$$
d=2 \times \sqrt{\frac{A}{\pi}}
$$
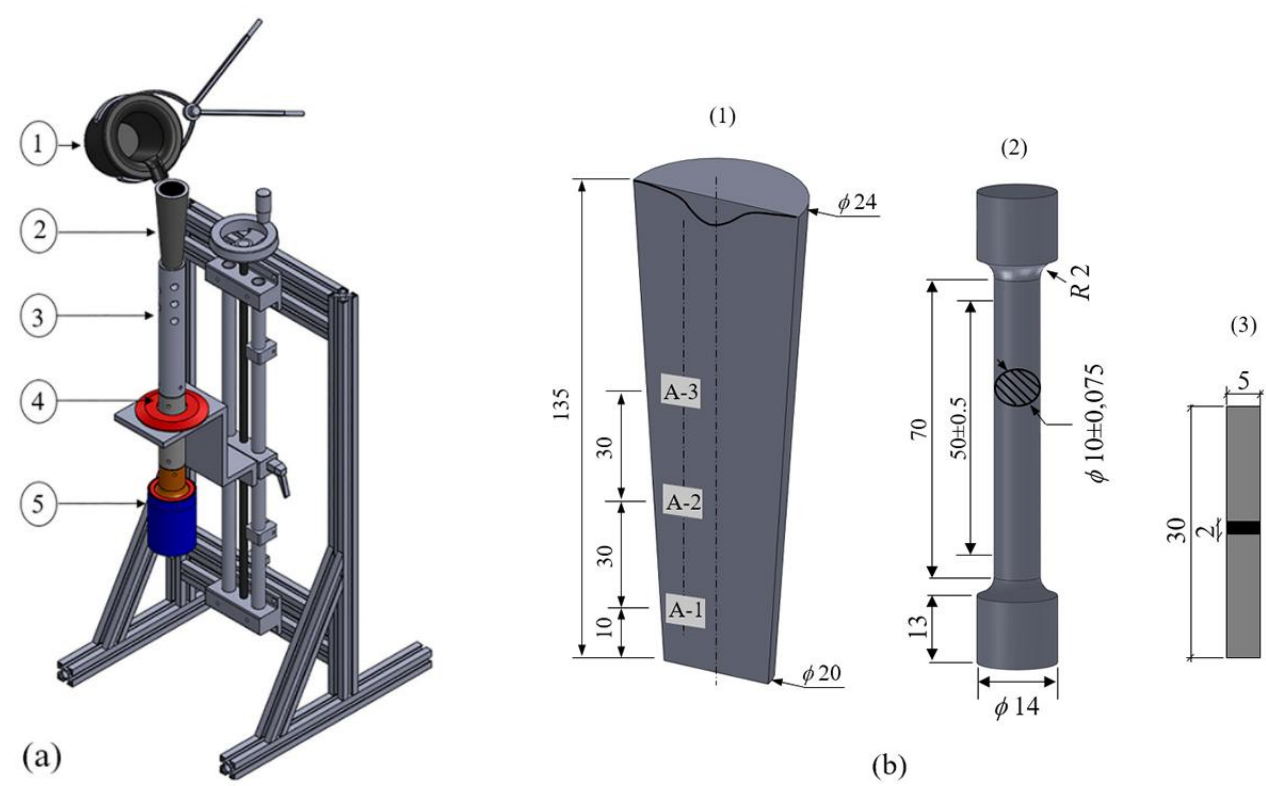

(b)

Fig. 1. (a) Experimental setup: (1) Crucible, (2) Steel Die, (3) Waveguide, (4) Booster and (5) 20kHz Transducer; (b) Cast Specimens: (1) Casting, (2) Tensile Sample and (3) DMA Sample.

\subsection{Mechanical characterization}

To characterize the static mechanical behavior for both experimental conditions, specimens were machined from the as-cast samples with a gauge length $L_{0}$ of $50 \mathrm{~mm}$ and a diameter of 10 mm (Fig. 1b (2)). Tensile tests were carried out at room temperature with $0.02 \mathrm{~s}^{-1}$ strain rate.

To determine the dynamic thermomechanical behavior, the $30 \times 5 \times 2 \mathrm{~mm}^{3}$ rectangular samples (Fig. 1b (3)) were tested using Dynamic Mechanical Analysis in a single-cantilever configuration. This type of test applies a sinusoidal load to the sample and monitors the resultant deformation, evaluating the energy accumulated in the material (E'- Storage modulus) and the energy that is lost in that process (E''- Loss modulus). Consequently, the damping capacity of the material can be evaluated determining its internal friction $\left(\mathrm{Q}^{-1}\right)$, according to Eq. (1).

The samples were tested using strain amplitude values from $1.25 \times 10^{-5} \mathrm{~mm} / \mathrm{mm}$ to $1.0 \times 10^{-3}$ $\mathrm{mm} / \mathrm{mm}$ with a frequency of $1[\mathrm{~Hz}]$. The strain amplitude values were selected to obtain 
damping values and monitor both independent and dependent strains and to characterize the value of critical strain, similarly to the technique used by Ali et al. [21]).

\section{Results and discussion}

\subsection{Microstructure}

Useful effects of ultrasonic melt processing are related to efficient transformation of electric energy (using an ultrasonic power supply or generator) into mechanical vibration by means of an ultrasonic transducer (operating in resonance), which is in the last step radiated to a liquid metal. During this process it is necessary to minimize thermal losses (in the ultrasonic generator, transducer and sonotrode) and maximize the real power load of acoustic energy on the liquid metal. Moreover, ultrasonically assisted melt degassing and refinement should be understood as the main objective, as the associated arising phenomenology is very complex. For instance, a small shift in temperature could present a high impact on the final process efficiency, namely in grain size of $\alpha-\mathrm{Al}$ as demonstrated by Puga et al. [4] and in the morphology of intermetallic phases as reported by Khalifa et al. [22]).

\section{$\underline{\alpha-A l \text { grain }}$}

Fig. 2 presents the microstructure of A17075 alloy processed by US, using $400 \mathrm{~W}$ electric power at different distances to waveguide/mold interface. According to the optical microstructure, it is clear that there is a significant difference on the grain size between nontreated (Fig.2a-c) and US treated (Fig. 2d-e) samples. This suggestion can be confirmed by Fig. 3 , which presents the grain size distribution of $\alpha-\mathrm{Al}$ in different positions along the samples (as indicated in Fig. 1b), for non-treated and US treated samples. Furthermore, according to Fig. 3 it is clear that with increasing distance to the US waveguide-die interface (increasing distance from $\mathrm{A} 1$ to $\mathrm{A} 3)$, there is no significant change/difference in both the average of $\alpha$-Al grain size and the dispersion around that value $(\mathrm{d}=100 \pm 20 \mu \mathrm{m}$ for non-treated and $\mathrm{d}=42 \pm 10 \mu \mathrm{m}$ for US treated samples) independently of the sample treatment. Although according to Eq. (6), the 
theoretical acoustic power density decreases with increasing distances from the interface (Position A1: $\mathrm{I}=127 \mathrm{~W} / \mathrm{cm}^{2}$; Position A2: $\mathrm{I}=115 \mathrm{~W} / \mathrm{cm}^{2}$; Position A3: $\mathrm{I}=105 \mathrm{~W} / \mathrm{cm}^{2}$ ), these values are higher than the minimum necessary to develop cavitation $\left(\mathrm{I}=2 \mathrm{~W} / \mathrm{cm}^{2}\right.$ is the threshold value considered by Eskin and Eskin [3] from which the cavitation phenomena is developed). This is the reason why there are no significant differences between the $\alpha$-Al grain size along the cast samples.

$$
I=\frac{P}{S}
$$



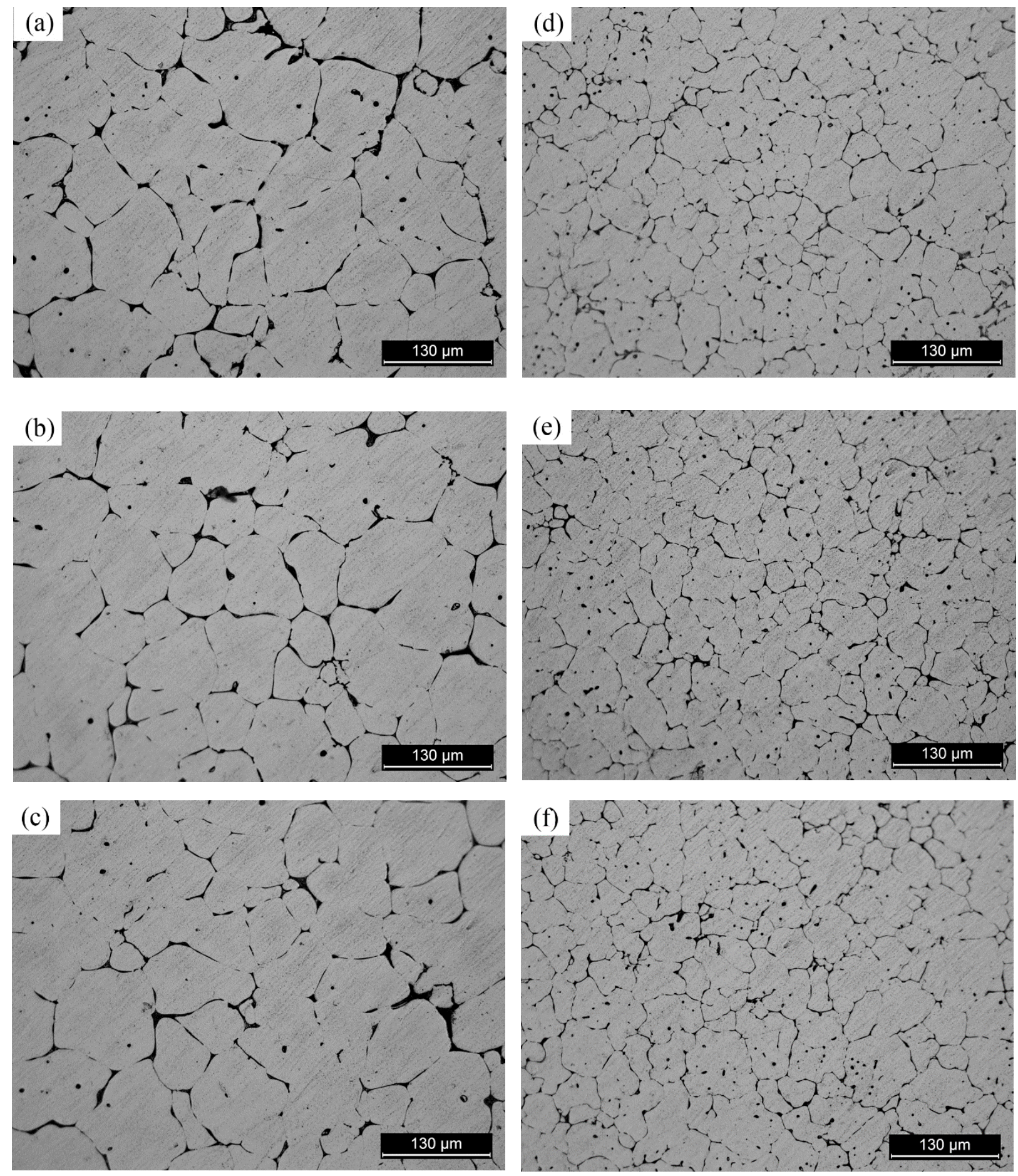

Fig. 2. Optical microstructures: (a, b and c) non-treated; (d, e and f) US treated. (a and d) Position A-1; (b and e) Position A-2; (c and f) Position A-3. 


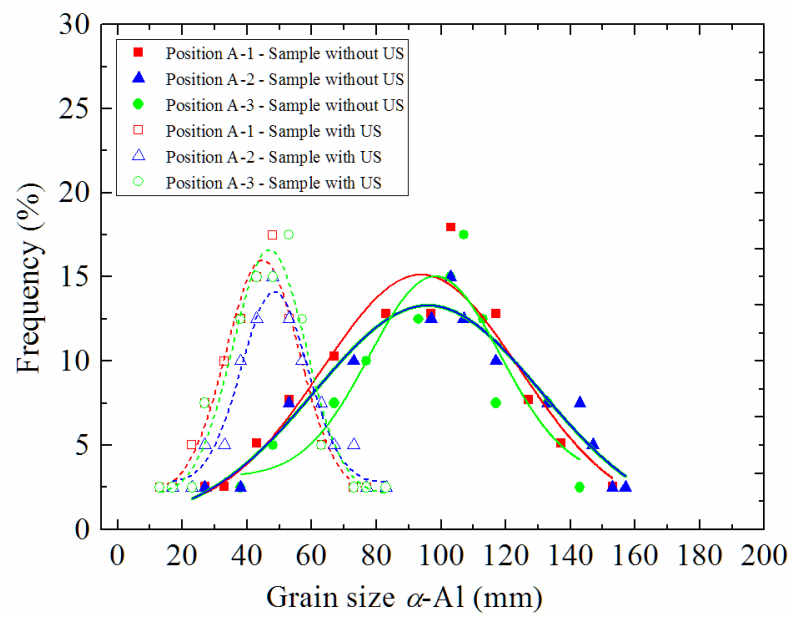

Fig. 3. Distribution of $\alpha$-Al grain size in different positions for non-treated and US-treated samples.

The effect of high intensity ultrasonic vibration on the grain refinement efficiency can be attributed to a conjugation of two mechanisms: acoustically induced heterogeneous nucleation and dendrite fragmentation, that can be described as follows:

(1) When acoustic energy is applied to a liquid metal at high enough intensity to induce pressure variation it initiates cavitation [Eskin], resulting in the formation of a large number of discontinuities or cavities (cavitation bubbles), that immediately start to expand and collapse. During expansion, the pressure inside the bubble increases and the temperature at the bubbles surface starts dropping. The decrease in temperature leads to undercooling at the bubbles surface which results in the formation of solid nuclei. At high pressure the bubbles collapse producing shock waves, known as acoustic streaming, which distribute the solid nuclei throughout the melt, promoting heterogeneous nucleation that result in the formation of a large number of small $\alpha-\mathrm{Al}$ grains (Fig.x).

(2) Below liquidus temperature, corresponding to the formation of the first solid metal, heterogeneous nucleation and acoustic streaming still occurs in the remaining liquid, although it's effect slows as temperature drops. Nevertheless, if dendritic grains still develop, the shock 
waves caused by the collapse of cavitation bubbles lead to fragmentation of dendritic cells at the dendrite roots, which are redistributed throughout the melt by acoustic streaming also increasing the number of new solidification nuclei, thus promoting themselves heterogeneous nucleation. The main difference between both mechanisms, is that dendrite fragmentation only occurs in melts already containing a minimum solid fraction volume, while acoustically induced heterogeneous nucleation can occur in melts with $100 \%$ liquid fraction volume.

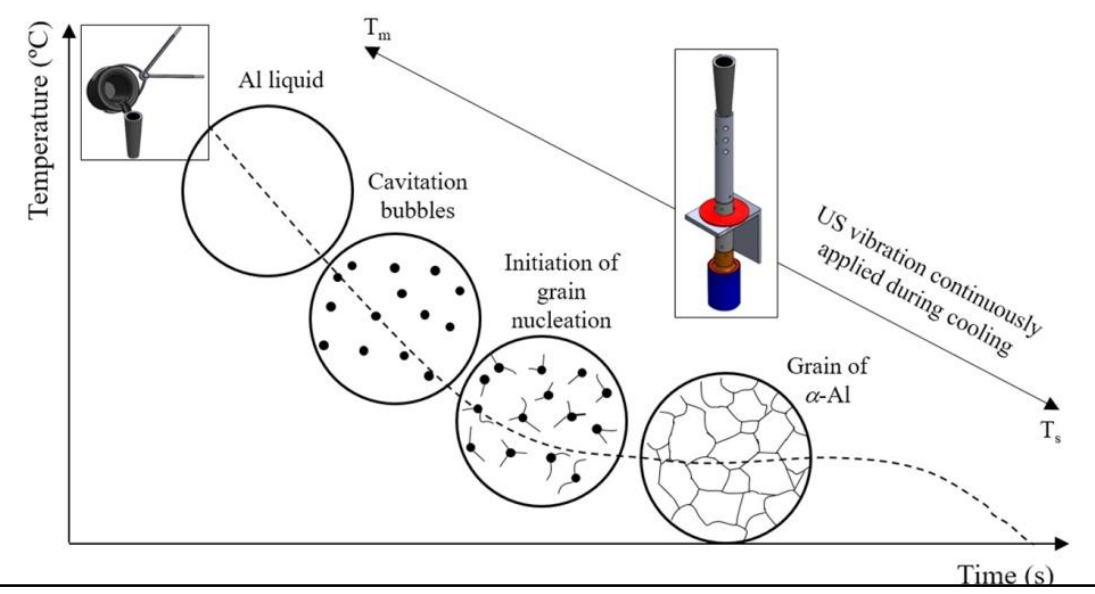

Figure $\mathrm{x}$ - Schematic representation of heterogeneous nucleation induced by ultrasonic cavitation

In metallic alloys, solidification nuclei are usually originated in the mould wall and grow to the bulk of the liquid metal. As the melt is superheated, the number of those nuclei that grow and survive is quite limited. Thus, in traditional solidification conditions, the probability of developing a large number of solidification nuclei and having them well dispersed within the melt simultaneously is quite low, which promotes the development of large grains that may have dendritic structure. In opposition, ultrasonic vibration and cavitation promote the development of nuclei directly in the sonicated bulk melt, thus completely changing the solidification sequence of the alloy when compared to the traditional solidification route. Moreover, melt stirring caused by ultrasonic vibration seems to increase heat dissipation from the bulk metal [ref 22], thus increasing the probability of solidification nuclei to survive. 
Furthermore, during US supply new nuclei are continually being generated to inoculate the melt and working as fresh solidification nuclei and growing fronts.

The coexistence of both mechanisms - heterogeneous nucleation and dendrite fragmentation - is then enough to promote a high density of nuclei in the melt [4], thus leading to the development of a large number of globular grains with small grain size as previously demonstrated by Puga et al. [23] and obtained in this work.

\section{$\underline{\text { Intermetallic compounds }}$}

Observing Figs. 2 and 3, it can be stated that the average grain size remains approximatly unchanged for different positions in the samples, thus the shape and distribution of the secondary phase is only analysed in position A-2.

Figs. 4 and 5 show the SEM secundary electron image of the as-cast 7075 alloy. It can be observed that the microstructure consists of $\alpha$-Al grains sorrounded by coarse precipitate particles in non-treated samples (Fig. 4) and fine precipitate particles in US treated samples (Fig. 5).
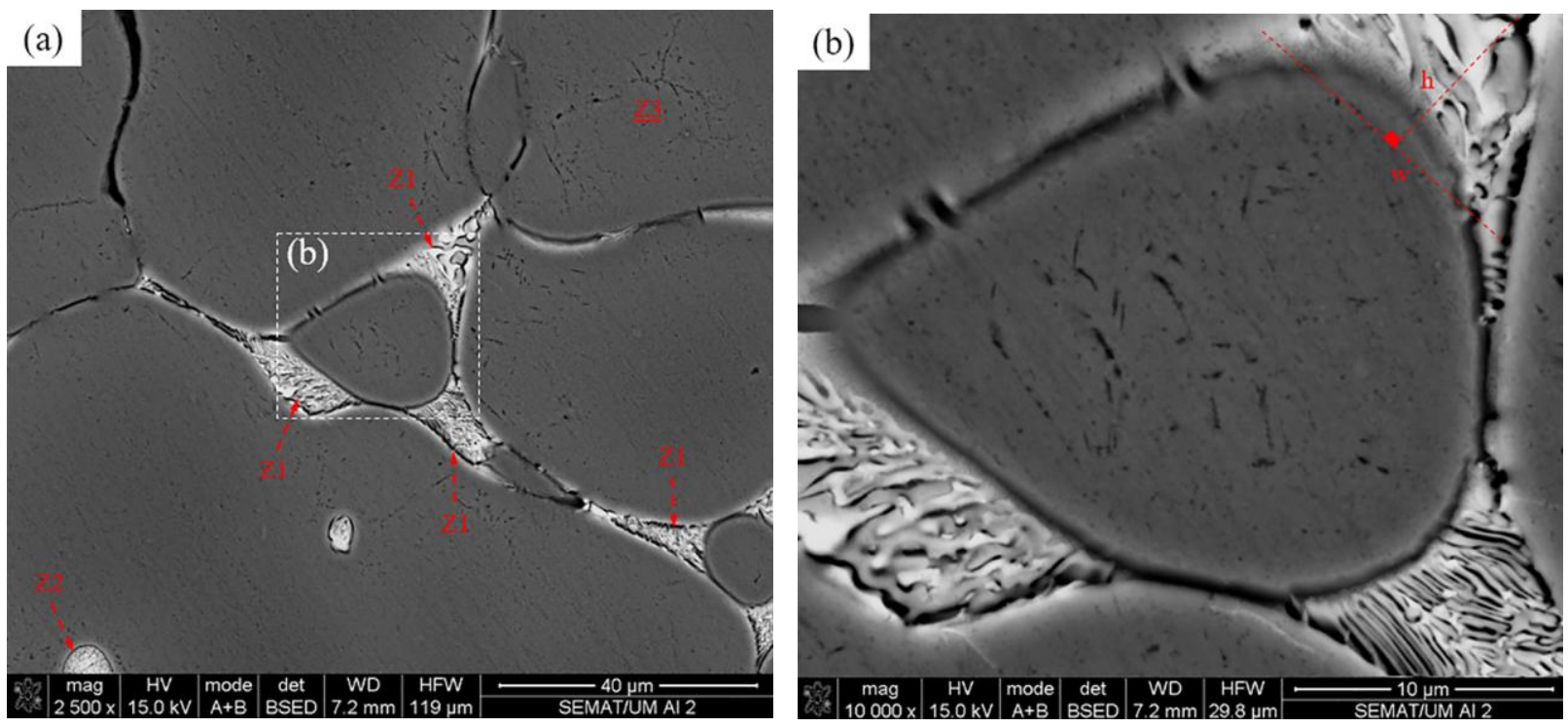
Fig. 4. Morphology and distribution of the intermetallic phase at Position A-2 obtained by SEM in non-treated samples. (a) Magnification of 2500x; (b) Detail of intermetallic phase surrounding grain.
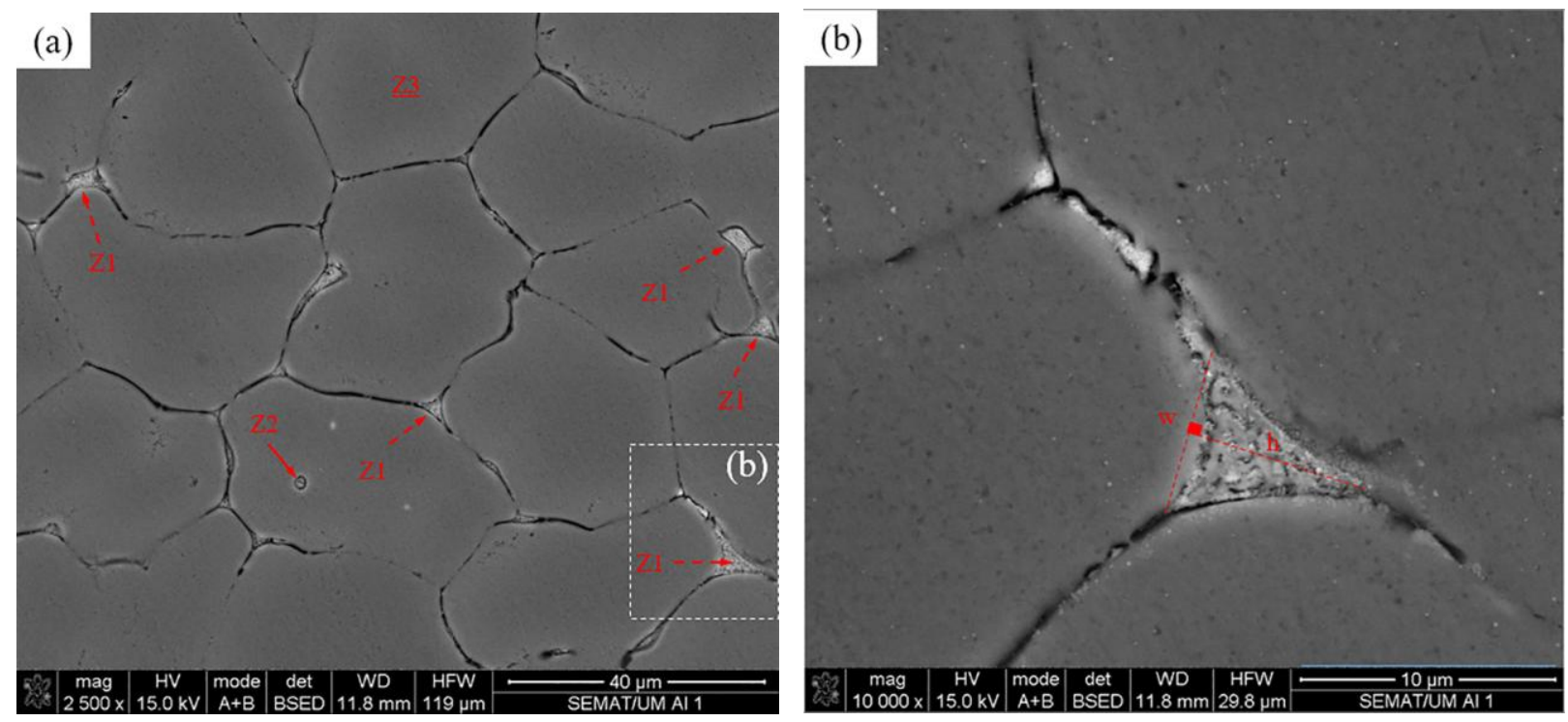

Fig. 5. Morphology and distribution of the intermetallic phase at Position A-2 obtained by SEM in US treated samples. (a) Magnification of 2500x; (b) Detail of intermetallic phase surrounding grain.

In the non-treated samples (Fig. 4), poured in traditional casting conditions, the precipitate height reaches about $\mathrm{h} \sim 20 \mu \mathrm{m}$ and boundary width $\mathrm{w} \sim 10 \mu \mathrm{m}$ (Table 1), which suggests that a post-cast homogenization by heat treatement would be difficult due to large interdendritic segregation. The main constituents of the interdendritic network were indentified by EDS (Fig. 6) as mostly lamellar eutectic $\mathrm{Al}-\mathrm{Cu}$ with small amount of $\mathrm{Mg}$ and $\mathrm{Zn}$, as well as insoluble Al$\mathrm{Cu}-\mathrm{Fe}$ compounds, identified respectively as $\mathrm{Z} 1$ and $\mathrm{Z} 2$ in Fig. 4a. The compounds identified as $\mathrm{Z1}$, are gerenally designated by lamellar eutectic $\mathrm{M}$ (often referred as $\eta$ ) and/or $\mathrm{T}(\mathrm{Al}, \mathrm{Cu}$, $\mathrm{Mg}, \mathrm{Zn}$ ), which are cored by copper-rich outer rims as refered by Lim et al. [24]. Moreover, the presence of these secondary phases is in accordance with the work of Su et al. [25]. In the US treated samples, the lamellar eutectic $\mathrm{Al}-\mathrm{Cu}$ are partially fragmented and adopt a more refined morphology ( $\mathrm{h} \sim 6 \mu \mathrm{m}$ and $\mathrm{w} \sim 5 \mu \mathrm{m})$ as presented in Fig. 5. Thus, the results suggest that the 
application of acoustic energy changes the morphology of the $\mathrm{M}$ and/or $\mathrm{T}$ ( $\mathrm{Al}, \mathrm{Cu}, \mathrm{Mg}, \mathrm{Zn}$ ) phases from lamellar eutectic colonies (Fig. 4b) to a fine blocky shape (Fig. 5b). Such modification can thus be atributed to fragmentation caused by US vibration or to constraint to their developement due to the higher number of $\mathrm{Al}$ grain boundaries or even a combination of both mechanisms. Nevertheless, to evaluate more precisely which is the predominant refinement mechanism further research is needed.
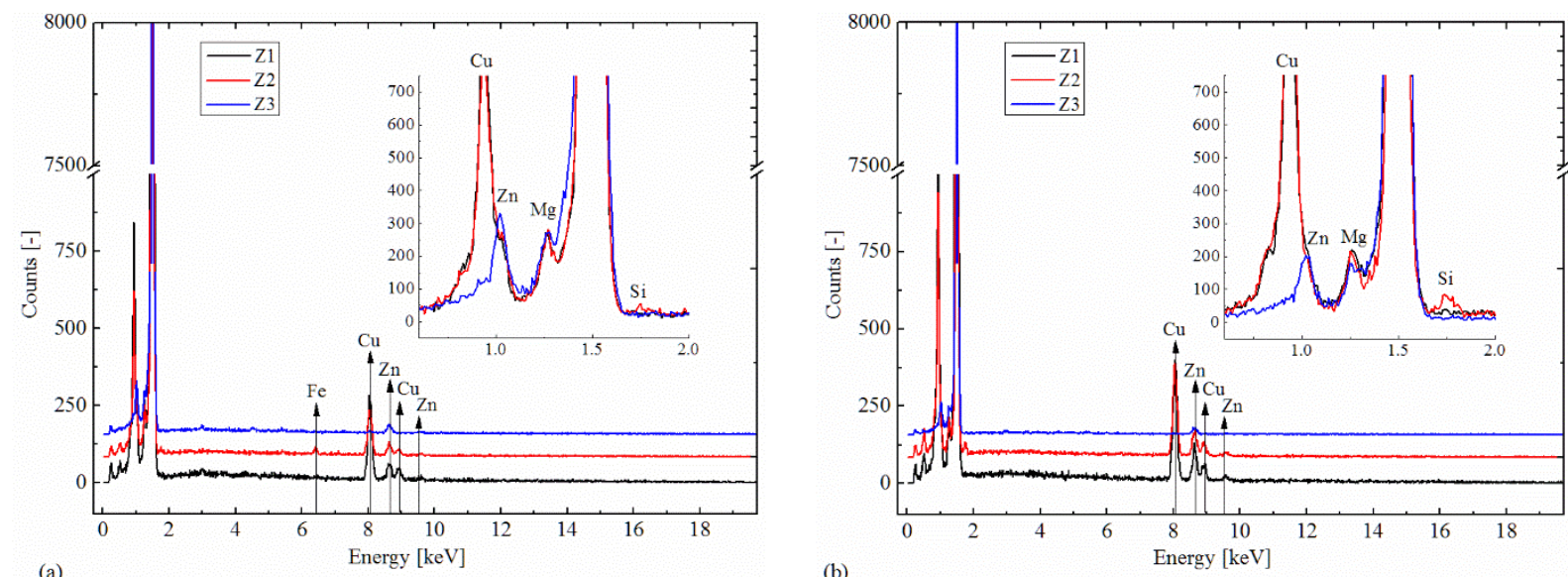

Fig. 6. EDS spectrum of the intermetallic phase and $\alpha-\mathrm{Al}$ (identified as Z1, Z2 and Z3 in Fig. 4 and 5): (a) non-treated and (b) US treated samples.

Table 1. Microstructural characteristics of non-treated and US treated samples.

\begin{tabular}{|c|c|c|c|}
\hline \multirow{2}{*}{ Samples } & \multicolumn{3}{|c|}{$\begin{array}{l}\text { Intermetallic Phase } \\
\text { (Z1 in Fig. } 4 \text { and 5) }\end{array}$} \\
\hline & $\begin{array}{c}\text { Volume } \\
\text { fraction }(\%)\end{array}$ & Relation $(\mathrm{h} \times \mathrm{w})$ & $\begin{array}{c}\text { Morphology } \\
(-)\end{array}$ \\
\hline Non-treated & $5.5 \pm 2.0$ & $\begin{array}{c}\sim 20.0 \times 10.0 \\
( \pm 1.5)\end{array}$ & $\begin{array}{l}\text { Lamellar } \\
\text { eutectic }\end{array}$ \\
\hline US treated & $6.0 \pm 1.0$ & $\begin{array}{l}\sim 6.0 \times 4.0 \\
( \pm 1.0)\end{array}$ & $\begin{array}{l}\text { Fine blocky } \\
\text { shape }\end{array}$ \\
\hline
\end{tabular}


Although the change in the morphology of these secondary phases is clear, its volume fraction and the characteristic triangular area shape in the vicinity of the Al grains is approximately the same in every sample. However, the refered tringular shape possesses an approximate area of $\mathrm{h} \times \mathrm{w}$ that in US treated samples is about $15 \%$ of the corresponding areas found in non-treated samples. Given the higher concentration of intermetallics ( $\mathrm{h} \times \mathrm{w}$ area) with a triangular form in non-treated samples and the near constant volume fraction values of secondary phases (Table 1), it is suggested that this phase is distributed allong the grain boundaries in US treated samples. In fact, US treatment does not supress the formation of intermetallic phases but refines them and homogenizes their distribution around a higher number of $\mathrm{Al}$ grains promoted by US vibration, keeping the fraction volume quite similar.

It can be observed in the EDS spectrum of the US treated samples that Fe seems to be absent in the phase indentified as Z2. This fact can be justified by the intense fragmentation and homogenization promoted by high acoustic power density $\left(>100 \mathrm{~W} / \mathrm{cm}^{2}\right)$, which refine and disperse the insoluble $\mathrm{Al}-\mathrm{Cu}-\mathrm{Fe}$ compounds within the $\alpha$ - $\mathrm{Al}$ grain in such small particles that EDS is no longer able to detect the elements in lower quantities (in this case $\mathrm{Fe}$ ).

Additional evidence of these transformation in the microstructure morphology can be observed in Fig. 7, that presentes the DSC results of heat flow versus temperature during heating to 700 ${ }^{\circ} \mathrm{C}$ at a rate of $20^{\circ} \mathrm{C} / \mathrm{min}$ for both processes. According to the results, both processes reveal an endothermic reaction, however the peak of US treated samples is delayed by approximately $2.5^{\circ} \mathrm{C}$. In terms of peak energy values, US treated samples have a decrease of $2.11 \mathrm{~J} / \mathrm{g}$, this being an evidence that the reaction temperature is decreased due to the finer distribution of the intermetallic phases. 


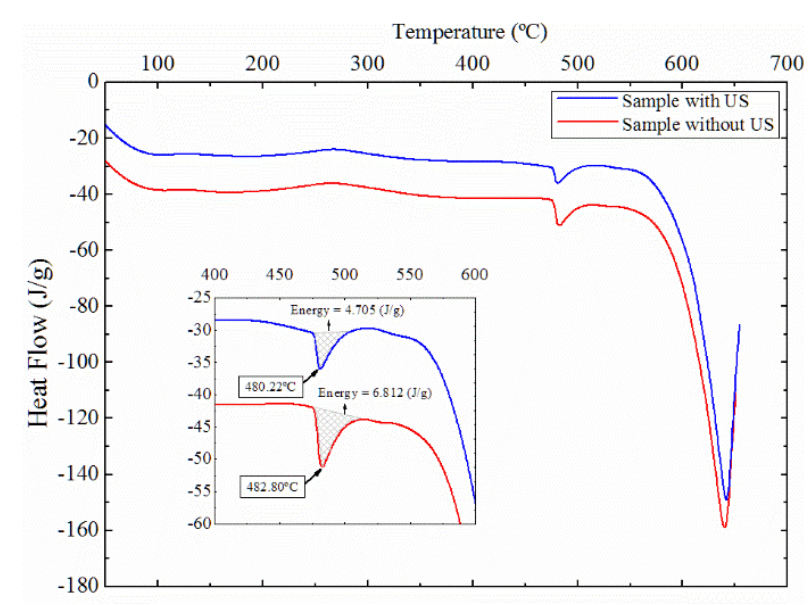

Fig. 7. DSC heat flow versus temperature results during heating at $20^{\circ} \mathrm{C}$ to $700^{\circ} \mathrm{C}$ in US treated and non-treated as-cast A17075 samples.

The high acoustic power density, promoted by US, generates an increase of internal energy of medium by high amplitude acoustic vibration. This justifies the refinement of the secondary phases and the increase in the thermal energy transfer to the surrounding environment, when compared with traditional casting condition (non-treated samples). As suggested by Lim et al. [24], the change in cooling rate, and the implication that this fact has on the precipitation mechanism of secondary phases, is essential in the variation of the dissolution energy $(\mathrm{J} / \mathrm{g})$. Thus, the additional energy introduced by vibration, generates an increasing in cooling rate which implies a reduction of the dissolution energy of the secondary phases as demonstrated in Fig.7.

\subsection{Static mechanical properties}

Table 2 presents the static mechanical properties of both US treated and non-treated samples, obtained by tensile testing. These experimental data have been obtained from the related mechanical properties test curves presented in Figure Y.

The values show that both UTS and elongation are enhanced by the US treatment. The lower values of mechanical properties in non-treated samples can be attributed to the presence of coarse grains and intermetallic segregation clusters, confirming the findings of Eskin and Eskin [3] and Puga et al. [4]. Since both processing routes included the same degassing process 
it is expected that the level of porosity and inclusions is similar in every sample, which can be confirmed by comparing figures 4 and 5. Thus, the grain size and morphology are the main contributors to the performance of the bulk material in terms of mechanical properties. Nevertheless, since the average grain size decreased in the US treated samples, the number of grains and grain boundaries is much higher on those samples, as it can be seen in Figures 2d-f), which increases the number of dislocations under stress. This factor also plays an important contribute to the increase of UTS that was verified on US treated samples. However, the increase of dislocations should have had a negative impact in elongation, which is not the case, as presented in Fig Y. The increase in elongation despite the increase in the number of dislocations can be attributed to the strong modification of the morphology of intermetallic phases promoted by the acoustic energy as referred before. In fact it is known that the presence of intermetallic phases in the shape of needles and platelets act as potential sites for decohesion failure during tensile loading, since they offer large area of decohesion, leading to a decrease in elongation to failure as demonstrated by Ceshini et al [ref nova]. On the other hand, small sized globular or polyhedral intermetallics (as they appear in the US treated samples) have less effect in crack initiation and decohesion during tensile loading as they usually form inside ductile dimples. Moreover, the presence of needle and platelet like intermetallics is usually associated to the presence of shrinkage porosity [Taylor et al (1999)], which also contribute to low values of elongation to failure. Thus, the increase in elongation is attributed to the combination of both effects - modification of intermetallics morphology and possible decrease of shrinkage porosity.

Table 2. Mechanical characteristics of non-treated and US treated samples.

\begin{tabular}{|c|c|c|c|c|c|}
\hline \multirow{4}{*}{ Samples } & \multicolumn{4}{|c|}{ Mechanical Properties } & \\
\hline & \multicolumn{2}{|c|}{ Present Sudy } & \multicolumn{3}{|c|}{ Bibliography } \\
\hline & UTS & Elong. & UTS & Elong. & \\
\hline & $(\mathrm{MPa})$ & $(\%)$ & $(\mathrm{MPa}$ & $(\%)$ & \\
\hline \multirow{2}{*}{ Non-treated } & \multirow{2}{*}{$172 \pm 20$} & \multirow{2}{*}{$1.2 \pm 0.2$} & 234 & 2 & Su et al. [25] \\
\hline & & & 246 & 1.73 & Rikhtegar and Ketabchi [26] \\
\hline US treated & $281 \pm 10$ & $2.3 \pm 0.2$ & - & - & \\
\hline
\end{tabular}




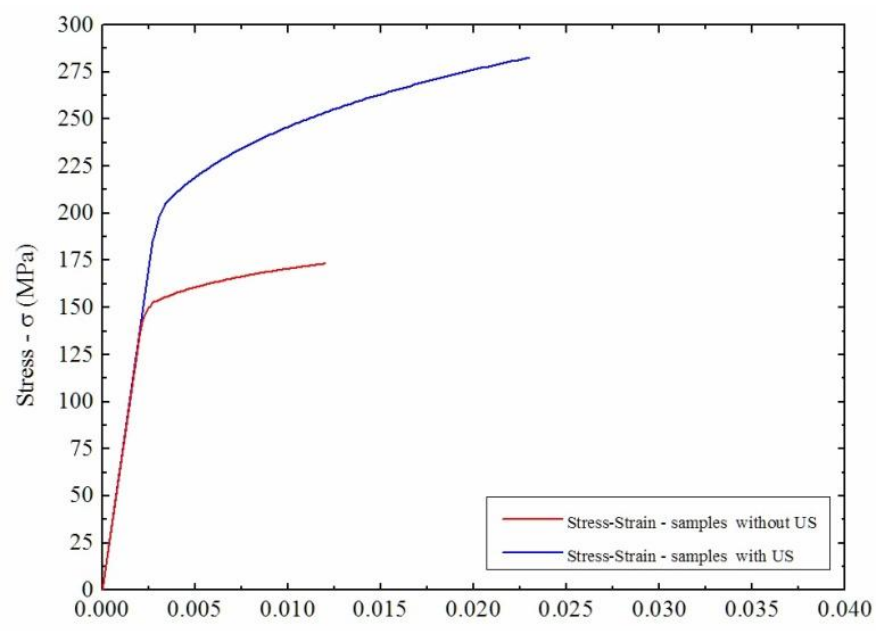

Figure Y - Stress-strain curves of US treated and non treated samples

Eq. (7) represents the Hall-Petch relation and states that the plastic flow stress $\left(\sigma_{\mathrm{y}}\right)$ is related to the mean grain size $(d)$, the friction stress of mobile dislocations $\left(\sigma_{0}\right)$ and to a characteristic constant that depends on the amount of impurities and alloying elements $\left(\mathrm{k}_{\mathrm{y}}\right)$. Given that, $\mathrm{k}_{\mathrm{y}}$ may be assumed as a constant and $\sigma_{0}$ is increased by the reduction of $\mathrm{d}$, it can be concluded that $\sigma_{\mathrm{y}}$ will increase with US treatment. This theory is in accordance with the obtained results, where US treated samples present a higher UTS (approximately 63\%), when compared with non-treated samples.

$$
\sigma_{y}=\sigma_{0}+k_{y} d^{-1 / 2}
$$

3.3 Dynamic mechanical properties

The internal friction of both US treated and non-treated samples as a function of strain amplitude is shown in Fig. 8a. These samples are characterized by a nearly linear strain independent behavior, until the critical strain amplitude is reached. At low strain amplitude values implie equally low stress states in the samples where dislocation motion is opposed by 
lattice drag [27]. According to Fig. 9, when a sample that is initially in balance (Fig. 9a) is subjected to a low strain amplitude oscilation the soft pinning points $\left(\mathrm{L}_{\mathrm{c}}\right)$ start to bow out and generate an internal friction that is strain independent (Fig. 9b-c). When the critical strain is reached, the hard pinning points $\left(\mathrm{L}_{\mathrm{n}}\right)$ begin to dislocate and the strain dependent internal friction regime is imposed (Fig. 9d-e) due to the hysteretic loss in the line segment dislocations [28] and the internal friction increases exponentially [29]. Further increasing the strain amplitude, will make that the pin network is activated as Frank-Read sources and the dislocation strain is irreversible and are generated in the plastic domain. However the imposed strain values in present tests were assured never to reach the plastic region. The resultant behavior of the samples is in accordance with the Granato-Lücke theory, displaying a linear relation between the logarithmic increase of strain dependent internal friction and the decrease in the inverse of strain amplitude (Fig. 8b). Given the linearity of the plots it is shown that the main damping mechanism in the samples is dislocation detachment [30].
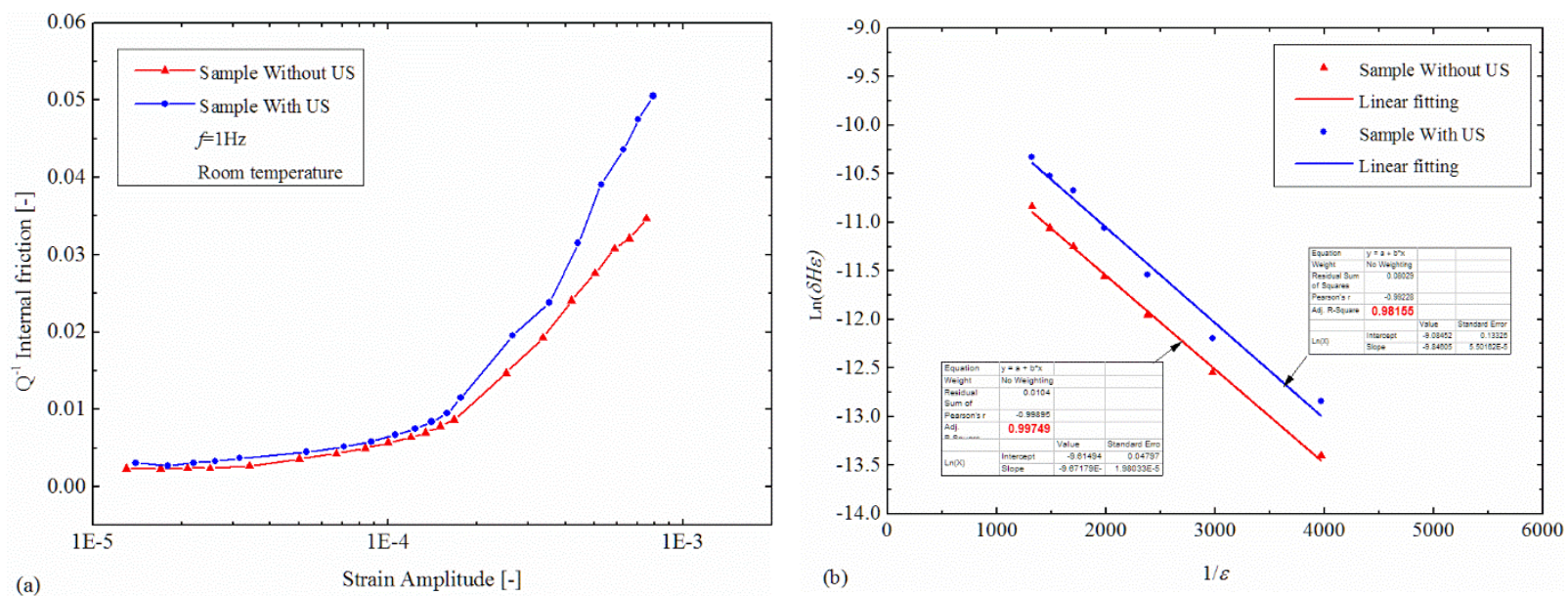

Fig. 6. Internal friction in US treated and non-treated samples: a) Strain amplitude and b) Granato-Lücke plots. 


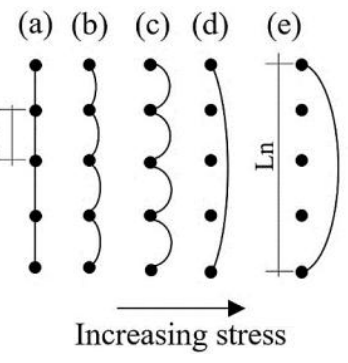

Fig. 7. Granato-Lücke model for dislocation (adapted from (Granato and Lücke, 1956)).

According to Fig. 8a, it is suggested that US treatment has no relevent effect in the overall strain independent values of internal friction. Although, the grain refinement and homogenization (Fig. 2) promoted by US treatment reduces the average length of soft pinning points and increases internal friction according to Eq. (3), the refinement and change of secondary phase reduces the dislocation density [31]. Thus, the impact of US treatment in the transformation of the alloy microstructure seems to generate opposite processes that allow the internal friction not to be significantly changed at a macroscopic level. This resemblance is maintained untill the critical strain amplitude is reached at $1.59 \times 10^{-4}$ for US treated samples and $1.68 \times 10^{-4}$ in non-treated samples.

However, further increasing the value of strain amplitude, it can be observed that the microstructural transformation promoted by US treatment generates a significant increase in the values of internal friction. The reduction of length between hard pinning points and the dispersion of the secundary phases allong the grain boundaries allows an increase in the dissipated energy. Although, there is loss of internal friction by absence of high-angles and coarse shape of both grain and secundary phase, there is an increase in the vicinities of graingrain and grain-secundary phases boundary length, shear stress and anelastic shear strain all promoters of damping [32]. Thus, as it would be expected given the previous considerations, it is visible in Fig. 8a an increase of internal friction in US treated samples, relatively to the ones that are non-treated. 


\section{Conclusion}

In this study, the effect of the Ultrasonic Treatment on the Microstructure and its role in the static and dynamic mechanical behavior of as-cast Al7075 alloy cast was investigated. The following conclusions were drawn:

(1) The effect of US treatment during solidification refines the $\alpha$-Al matrix and the intermetallic phase clusters.

(2) The use of high acoustic power density promotes a uniform dispersion of the equilibrium phases of soluble $\mathrm{M}$ and/or $\mathrm{T}(\mathrm{Al}, \mathrm{Cu}, \mathrm{Mg}, \mathrm{Zn})$ and their insoluble $\mathrm{Al}-\mathrm{Cu}-\mathrm{Fe}$ compounds, changing its morphology from lamellar eutectic to a fine blocky shape.

(3) US treatment promoted the dispersion of the intermetallic phases, as well as the reduction of their height and width relation due to enhanced interdendritic segregation.

(4) Static tensile testing shows an increase of both tensile strength (63\%) and strain (92\%) when processing the alloys by US.

(5) It was shown that both US treated and non-treated samples have a dislocation mechanism that is in according with Granato-Lücke theory. However, US treated samples show enhance internal friction after the critical strain amplitude.

(6) US treatment in the A17075 samples seems to improve both static and dynamic mechanical properties. It is suggested that this kind of treatment can be a promising solution to process materials to obtain high damping and high strength characteristics.

\section{Acknowledgements}

This research was supported by FEDER/COMPETE funds and by national funds through FCT Portuguese Foundation for Science and Technology and was developed on the aim of the research Post-Doctoral grant SFRH/BPD/76680/2011. Also, this work has been supported by the FCT in the scope of the project: UID/EEA/04436/2013.

\section{References}


[1] T. Liu, Q. Wang, Y. Sui, Q. Wang, and W. Ding, Mater. Des. 68, 8(2015).

[2] H. Puga, J. Barbosa, N.Q. Tuan, and F. Silva, Trans. Nonferrous Met. Soc. China 24, 3459(2014).

[3] G.I. Eskin, and D.G. Eskin, Ultrasonic treatment of light alloy melt, CRC Press, Boca Raton (2014).

[4] H. Puga, S. Costa, J. Barbosa, S. Ribeiro, and M. Prokic, J. Mater. Process. Technol. 211, 1729(2011).

[5] N. Ono, R. Nowak, and S. Miura, 2004. Mater. Lett. 58, 39(2004).

[6] X. Li, S.M. Xiong, and Z. Guo, J. Mater. Sci. Technol. 32, 54(2016).

[7] J. Zhang, M.N. Gungor, and E.J. Lavernia, J. Mater. Sci. 28, 1515(1993).

[8] M. Colakoglu, J. Theor. Appl. Mech. 42, 95(2004).

[9] W.B. Jiang, Q.P. Kong, P. Cui, Mater. Sci. Eng. A 527, 6028(2010).

[10] M. Blanter, I. Golovin, H. Neuhauser, and H. Sinning, Internal friction in metallic materials, Springer, New York (2007).

[11] A.J. Filmer, G.J. Hutton, and T.S. Hutchison, J. Appl. Phys. 29, 146 (1958).

[12] A. Granato, and K. Lücke, J. Appl. Phys. 27, 583 (1956).

[13] L. Lihua, Z. Xiuqin, L. Xianfeng, W. Haowei, and M. Naiheng, Mater. Lett. 61, 231(2007).

[14] H. Watanabe, A. Owashi, T. Uesugi, Y. Takigawa, and K. Higashi, Philos. Mag. 91, 4158(2011).

[15] G.D. Fan, M.Y. Zheng, X.S. Hu, K. Wu, W.M. Gan, and H.G. Brokmeier 2013. Mater. Sci. Eng. A 561, 100(2013).

[16] R.H. Randall, and C. Zener, Phys. Rev. 58, 472(1940).

[17] X. Cao, and C. Huang, Mater. Sci. Eng. A 383, 341(2004).

[18] Y. Chen, Q. Wang, J. Lin, M. Liu, J. Hjelen, and H.J. Roven, Trans. Nonferrous Met. Soc. China 24, 3747(2014).

[19] Y.C. Lee, A.K. Dahle, and D.H. StJohn, Metall. Mater. Trans. A 31, 2895(2000). 
[20] N.Q. Tuan, H. Puga, H., J. Barbosa, and A.M.P. Pinto, Met. Mater. Int. 21, 72(2015).

[21] Y. Ali, D. Qiu, B. Jiang, F. Pan, and M.-X. Zhang, J. Alloys Compd. 619, 639(2015).

[22] W. Khalifa, Y. Tsunekawa, and M. Okumiya, J. Mater. Process. Technol. 210, 2178(2010).

[23] H. Puga, J. Barbosa, S. Costa, S. Ribeiro, A.M.P. Pinto, and M. Prokic, Mater. Sci. Eng. A 560, 589(2013).

[24] S.T. Lim, I.S. Eun, and S.W. Nam, Mater. Trans. 44, 181(2003).

[26] F. Rikhtegar, and M. Ketabchi, Mater. Des. 31, 3943(2010).

[25] X. Su, S.J. Wang, X. OuYang, P. Song, G.M. Xu, and D.H. Jiang, 2014. Mater. Sci. Eng. A 607, 10(2014).

[27] J. Gittus, Creep, viscoelasticity, and creep fracture in solids, Wiley, New York (1975).

[28] A. Wolfenden, and J. Wolla, J. Mater. Sci. 24, 3205(1989).

[29] X.S. Hu, K. Wu, M.Y. Zheng, W.M. Gan, and X.J. Wang, Mater. Sci. Eng. A 452, 374(2007).

[30] K. Nishiyama, R. Matsui, Y. Ikeda, S. Niwa, and T. Sakaguchi, 2003. Proc. Int. Symp. High Damping Mater. 355, 22(2003).

[31] D. Shenglong, L. Dabo, W. Tianzhen, and L. Chunyu, J. Mater. Sci. 33, 2227(1988).

[32] M. Tanaka, and H. Iizuka, J. Mater. Sci. 26, 4389(1991). 


\section{Capitations Figures}

Fig. 8. (a) Experimental setup: (1) Crucible, (2) Steel Die, (3) Waveguide, (4) Booster and (5)

20kHz Transducer; (b) Casted Specimens: (1) Casting, (2) Tensile Sample and (3) DMA Sample.

Fig. 9. Optical microstructures: (a, b and c) non-treated; (d, e and f) US treated. (a and d) Position A-1; (b and e) Position A-2; (c and f) Position A-3.

Fig. 10. Distribution of $\alpha$-Al grain size in different positions for non-treated and US-treated samples.

Fig. 11. Morphology and distribution of the intermetallic phase at Position A-2 obtained by SEM in non-treated samples. (a) Magnification of 2500x; (b) Detail of intermetallic phase surrounding grain.

Fig. 12. Morphology and distribution of the intermetallic phase at Position A-2 obtained by SEM in US treated samples. (a) Magnification of 2500x; (b) Detail of intermetallic phase surrounding grain.

Fig. 6. EDS spectrum of the intermetallic phase and $\alpha$-Al (identified as Z1, Z2 and Z3 in Fig. 4 and 5): (a) non-treated and (b) US treated samples.

Fig. 7. DSC heat flow versos temperature results during heating at $20^{\circ} \mathrm{C}$ to $700^{\circ} \mathrm{C}$ in US treated and non-treated as-cast A17075 samples.

Fig. 13. Internal friction in US treated and non-treated samples: a) Strain amplitude and b) Granato-Lücke plots.

Fig. 14. Granato-Lücke model for dislocation (adapted from (Granato and Lücke, 1956)). 